\title{
Internal Carotid Vasospasm during Mechanical Thrombectomy
}

Carolina B Maciel ${ }^{1 *}$, Benjamin N Blond ${ }^{1}$, David M Greer ${ }^{1}$

Department of Neurology, Yale-New Haven Hospital, Yale School of Medicine, New Haven, USA

*Corresponding author: Carolina Barbosa Maciel, Department of Neurology, Yale- New Haven Hospital 15 York Street, Building LCl, 10 th Floor, Suite 1003, New Haven, CT 06520; Tel: 203-785-3892; Fax: 203-737-4419; Email: carolina.maciel@yale.edu

Received date: August 20, 2015; Accepted date: August 22, 2015; Published date: August 27, 2015

Copyright: (2015 Maciel CB et al. This is an open-access article distributed under the terms of the Creative Commons Attribution License, which permits unrestricted use, distribution, and reproduction in any medium, provided the original author and source are credited.

\section{Image Description}

A 23-year-old woman 6 weeks post-partum with a history of systemic lupus erythematosus on immunosuppressant medications was admitted with a dense left hemiparesis, homonymous hemianopsia, hemineglect and sensory loss, and a right gaze preference in the setting of an acute proximal right middle cerebral artery (MCA) occlusion. She presented outside of the time window for systemic intravenous thrombolysis, and was taken for endovascular rescue therapy with a clot retrieval device. Figures $1 \mathrm{~A}$ and B show the initial normal caliber of her right internal carotid artery and an abrupt MCA cut off (arrow) on anterior-posterior and lateral views, respectively. After one pass with the Solitaire ${ }^{\mathrm{ix}}$ device, she developed angiographically significant vasospasm as demonstrated by Figure $1 \mathrm{C}$ and 1D (arrow head). The procedure achieved improvement of flow in the MCA after local administration of intra-arterial tissue plasminogen activator (not shown), but was complicated by mild hemorrhagic transformation, which was clinically asymptomatic. Unfortunately, no significant clinical improvement was noted.

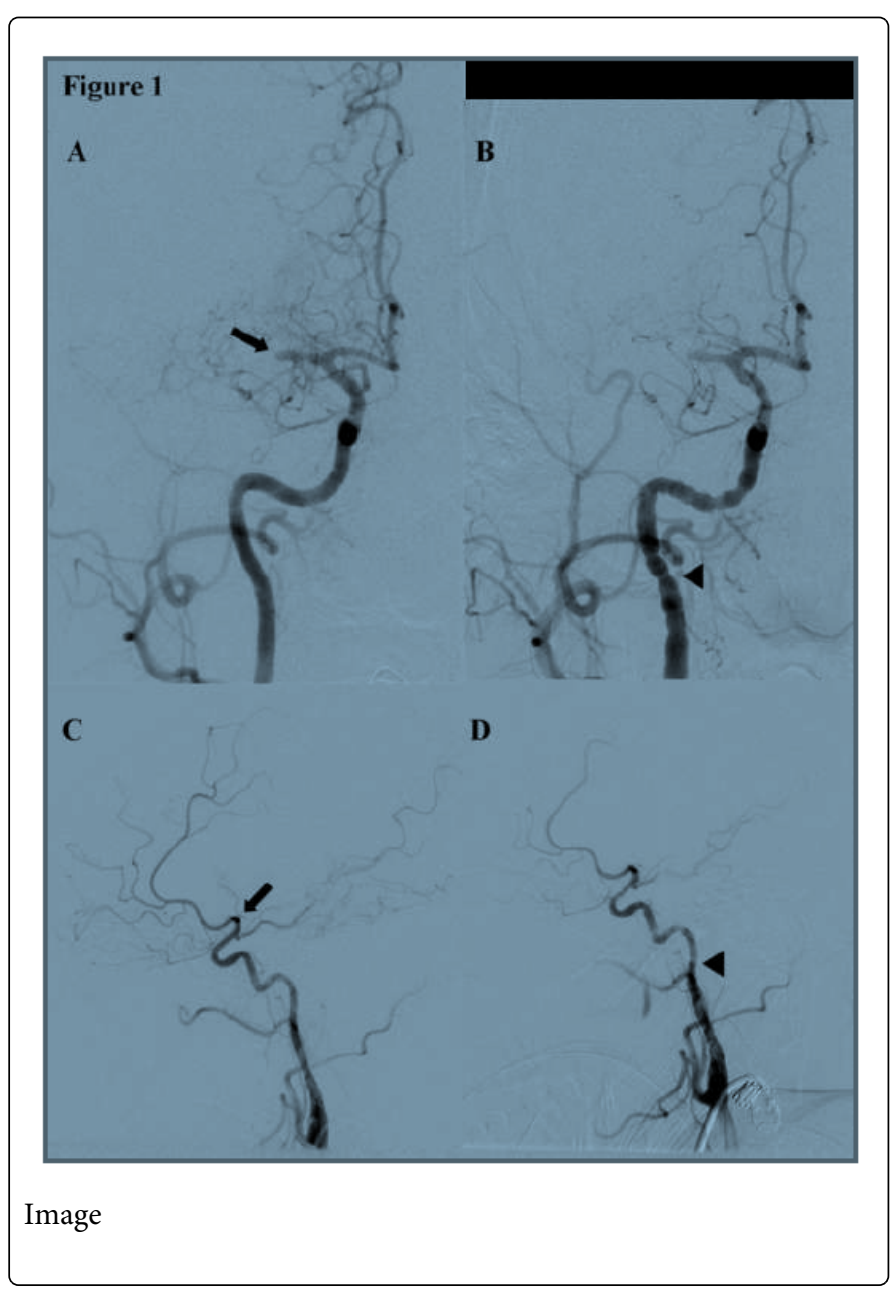

Arterial spasm of the target vessel is a well-known phenomenon related to manipulation of the vessel wall during both introduction and withdrawal of instruments [3]. The incidence of vasospasm during intra-arterial procedures is estimated between 13-32\% [1-4] and is typically a self-limited complication without clinical consequences, rarely requiring specific treatment such as local vasoactive drug administration [1-3]. To date, there is no data to support a significant association between the number of mechanical thrombectomy passes and the development of vasospasm1. Some institutions use vasodilators, including glyceroltrinitrate, during device withdrawal in an attempt to prevent vasospasm1, although this has not yet been specifically investigated. 
Citation: Maciel CB, Blond BN, Greer DM (2015) Internal Carotid Vasospasm during Mechanical Thrombectomy. J Neurol Neurophysiol 6: i103.

Page 2 of 2

\section{References}

1. Kurre W, Pérez MA, Horvath D, Schmid E, Bäzner H, et al. (2013) Does mechanical thrombectomy in acute embolic stroke have long-term side effects on intracranial vessels? An angiographic follow-up study. Cardiovasc Intervent Radiol 36: 629-636.

2. Dorn F, Stehle S, Lockau H, Zimmer C, Liebig T(2012) Endovascular treatment of acute intracerebral artery occlusions with the solitaire stent: single-center experience with 108 recanalization procedures. Cerebrovasc Dis 34: 70-77.

3. Roth C, Papanagiotou P, Behnke S, Walter S, Haass A, et al. (2010) Stentassisted mechanical recanalization for treatment of acute intracerebral artery occlusions. Stroke 41:2559-2567.

4. Machi P1, Costalat V, Lobotesis K, Maldonado IL, Vendrell JF, et al. (2012) Solitaire FR thrombectomy system: immediate results in 56 consecutive acute ischemic stroke patients. J Neurointerv Surg 4: 62-66. 